\title{
A geometric approach to determine adsorption and desorption kinetic constants
}

\author{
Wen-Hui Kuan ${ }^{\mathrm{a}, *}$, Shang-Lien Lo ${ }^{\text {a }}$, Chia M. Chang ${ }^{\mathrm{b}}$, Ming K. Wang ${ }^{\mathrm{b}}$ \\ a Graduate Institute of Environmental Engineering, National Taiwan University, Taipei 106, Taiwan, ROC \\ ${ }^{\mathrm{b}}$ Department of Agricultural Chemistry, National Taiwan University, Taipei 106, Taiwan, ROC
}

Received 29 November 1999; accepted 8 February 2000

\begin{abstract}
A geometric method based on Langmuir kinetics has been derived to determine adsorption and desorption kinetic constants. In the conventional procedure, either the adsorption kinetic constant $\left(k_{\mathrm{a}}^{\mathrm{c}}\right)$ or desorption kinetic constant $\left(k_{\mathrm{d}}^{\mathrm{c}}\right)$ is found from kinetic experiments and the other is calculated by their correlation with the equilibrium constant, i.e, $k_{\mathrm{d}}^{\mathrm{c}}=K_{\text {con }} / k_{\mathrm{a}}^{\mathrm{c}}$, where $K_{\mathrm{con}}$ has been known from equilibrium studies. The determined constants $\left(K_{\mathrm{con}}, k_{\mathrm{a}}^{\mathrm{c}}, k_{\mathrm{d}}^{\mathrm{c}}\right)$, if based only on the conventional procedure, may not be accurate due to their mathematical dependence. Therefore, the objectives of this study are applying a geometric approach to directly determine Langmuir kinetic constants and describe adsorption behavior. In this approach, both adsorption kinetic constant $\left(k_{\mathrm{a}}^{\mathrm{g}}\right)$ and desorption kinetic constant $\left(k_{\mathrm{d}}^{\mathrm{g}}\right)$ are obtained only from data of kinetic experiments, and a geometric equilibrium constant $\left(K_{\text {geo }}\right)$ is calculated by $K_{\text {geo }}=k_{\mathrm{a}}^{\mathrm{g}} / k_{\mathrm{d}}^{\mathrm{g}}$. The deviation between $K_{\text {geo }}$ and $K_{\text {con }}$ can prove the accuracy of $k_{\mathrm{a}}^{\mathrm{g}}$ and $k_{\mathrm{d}}^{\mathrm{g}}$ which were determined by this method. This approach was applicable to selenate, selenite and $\mathrm{Mg}^{2+}$ adsorption onto $\mathrm{SiO}_{2}$ regardless of whether the adsorbate formed inner- or outer-sphere complexes. However, this method showed some deviation between $K_{\text {con }}$ and $K_{\text {geo }}$ for $\mathrm{Mn}^{2+}$ adsorption because of the formation of surface $\mathrm{Mn}$ (II)-hydroxide clusters, which was inconsistent with the basic assumption of this method of monolayer adsorption. (c) 2000 Elsevier Science Ltd. All rights reserved.
\end{abstract}

Keywords: Langmuir kinetics; Adsorption; Desorption; Kinetic constant; Equilibrium constant

\section{Introduction}

Adsorption and desorption reactions are known to be important in many heterogeneous systems (Sparks, 1988; Suzuki, 1990; Mizuno and Misono, 1998). In aqueous and soil environments, the fate of ions is governed via adsorption/desorption reactions occurring at the interface between the liquid/solid phase (Lin and Benjamin, 1992). It has also been suggested that preliminary adsorption is a prerequisite for highly efficient heterogeneous catalysis (Fox and Dulay, 1993; Hoffmann et al., 1995). With regards to adsorption/

\footnotetext{
${ }^{*}$ Corresponding author. Fax: +886-2-2392-8821.

E-mail address:d4541005@ms.cc.ntu.edu.tw(W.-H.Kuan).
}

desorption reactions, thermodynamic data only provide the information about final state of a system, such as adsorption capacity and equilibrium constant, but kinetics deals with changes in chemical properties in time and is concerned especially with rates of change. Because the chemical equilibrium is a balance between forward and reverse rates of reaction, the concept of equilibrium constant is derived from kinetic concepts of mass action rather than vice versa (Moore and Pearson, 1981). Based on this aspect, equilibrium and kinetic (forward and reverse) constants can be determined through complete kinetic measurements. Unfortunately, the complexities are such that the theory of chemical kinetics is difficult to apply with accuracy except using the state-of-the-art and expensive apparatus (Steinfeld et al., 1999). As a result, thermodynamic studies are necessary for 
determining the equilibrium constant and kinetic measurements only deal with the rate of reaction. It also means that time-consuming experimental works must be performed in classical methods for predicting adsorption equilibrium and kinetic constants.

In general, the batch technique is the most popular method of adsorption/desorption kinetic study and sets the groundwork for detailed experiments. A number of equations, such as the first-order, Elovich, parabolic diffusion, zero-order, two-constant rate, LangmuirHinshelwood, and first-order Langmuir equation, have been used to describe adsorption kinetic reactions and calculate rate constants in batch experimental data (Moore and Pearson, 1981; Dzombak and Morel, 1986; Sparks, 1986; 1988; Al-Ekabi et al., 1989; Rate et al., 1993; Davis and Upadhyaya, 1996; McLaren et al., 1998). One can determine either adsorption or desorption constants from above-mentioned equations, and yields another constant by

$k_{\mathrm{d}}^{\mathrm{c}}=K_{\text {con }} / k_{\mathrm{a}}^{\mathrm{c}}$ or $\quad k_{\mathrm{a}}^{\mathrm{c}}=K_{\text {con }} / k_{\mathrm{d}}^{\mathrm{c}}$,

where $k_{\mathrm{a}}^{\mathrm{c}}$ and $k_{\mathrm{d}}^{\mathrm{c}}$ are the rate constants for the forward adsorption and reverse desorption reactions, and $K_{\text {con }}$ is the equilibrium constant determined from fitting these conventional equations to equilibrium experimental data. Since the equilibrium constant is necessary to calculate kinetic constants, the adsorption and desorption constants cannot be independently determined, revealing that the accuracy of kinetic constants and the equilibrium constants cannot be assessed because of their mathematical dependence.

$\mathrm{SiO}_{2}$ is the most abundant oxide in the earth crust and can significantly influence a variety of nutrients and pollutants in aquatic or soil environments (Reid and NcDuffie, 1981; Anderson and Benjamin, 1990). Moreover, $\mathrm{SiO}_{2}$ is also widely applied to many industrial processes for instance as filtration medium in water treatment plant and base substrate in catalyst (Kuan et al., 1998; Pullukat and Hoff, 1999). Therefore, ions adsorption/ desorption onto $\mathrm{SiO}_{2}$ surface are important in a number of areas that are of scientific and technological relevance.

As a consequence, the objectives of this study are:

1. to derive a simply geometric method to directly calculate both adsorption and desorption kinetic constants without using the equilibrium constant;

2. to describe adsorption behavior and final state via kinetic measurements;

3. to apply this method to several cases of ion adsorption/desorption onto $\mathrm{SiO}_{2}$.

\section{Theory development}

Most adsorption and desorption reactions can be described by

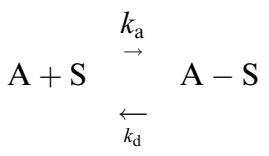

where $k_{\mathrm{a}}$ and $k_{\mathrm{d}}$ are the adsorption and desorption rate constants, A represents the adsorbent, $\mathrm{S}$ is the adsorbate, and $\mathrm{A}-\mathrm{S}$ is the adsorbate sorbed onto the adsorbent. For developing the quantitative theory of adsorption, Langmuir (1918) expressed adsorption and desorption kinetics as

$v_{\mathrm{a}}=k_{\mathrm{a}} x(1-\theta)$,

$v_{\mathrm{d}}=k_{\mathrm{d}} \theta$,

where $\theta$ is the coverage fraction $(0 \leqslant \theta \leqslant 1)$ and $x$ is the final equilibrium concentration of solute. When a solute is equilibrated with a surface, the adsorption rate $\left(v_{\mathrm{a}}\right)$ must be equal to the desorption rate $\left(v_{\mathrm{d}}\right)$. This relationship is illustrated schematically in Fig. 1(a).

Fig. 1(b) is a typical $\theta$ versus time $(t)$ relationship resulting from a conventional kinetic experiment. This curve can be divided into a fore fast reaction interval and a latter slow reaction interval. A linear regression analysis of data collected from the early stage will yield a slope $k_{0}$, namely initial adsorption rate; and the intercept of linearization of data in the late stage gives the equilibrium coverage fraction $\left(\theta_{\mathrm{e}}\right)$ :

$\theta=k_{0} t$

$\theta=\theta_{\mathrm{e}}$.

Combining Eqs. (5) and (6) gives

$t_{\mathrm{e}}=\frac{\theta_{\mathrm{e}}}{k_{0}}$,

where $t_{\mathrm{e}}$ refers to initial equilibrium time.

Replacing $\theta$ in Eqs. (3) and (4) with Eq. (5) yields

$v_{\mathrm{a}}=k_{\mathrm{a}} x\left(1-k_{0} t\right)$,

$v_{\mathrm{d}}=k_{\mathrm{d}} k_{0} t$.

At equilibrium,

$k_{\mathrm{a}} x\left(1-k_{0} t\right)=k_{\mathrm{d}} k_{0} t$.

Figs. 1(a) and (b) can be incorporated as Fig. 1(c). It is readily seen that $\theta_{\mathrm{e}}$ is identical to the shaded zone in Fig. 1(c), which can be expressed mathematically as

$\theta_{\mathrm{e}}=\int_{0}^{t_{\mathrm{e}}}\left(v_{\mathrm{a}}-v_{\mathrm{d}}\right) \mathrm{d} t$.

Substituting $v_{\mathrm{a}}$ and $v_{\mathrm{d}}$ with Eqs. (8) and (9), respectively, gives 
(a)

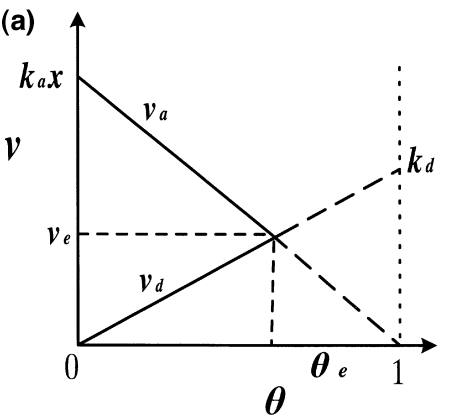

(b)

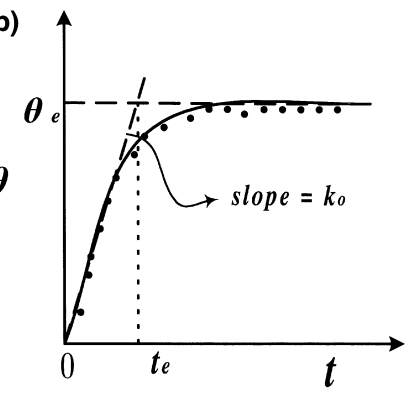

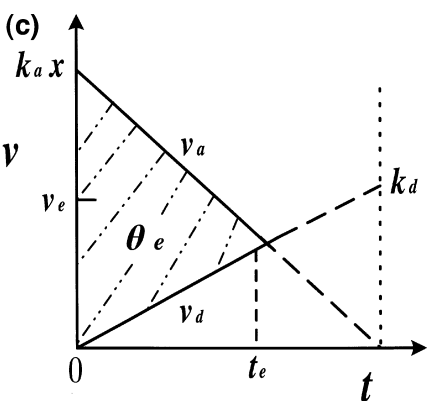

Fig. 1. (a) Schematic diagram of reaction rate as a function of surface coverage fraction (adapted from Langmuir kinetic equation (Langmuir, 1918)). (b) Schematic diagram of typical results of a conventional kinetic experiment. $k_{0}$ is the slope of the regression line for the early stage, $\theta_{\mathrm{e}}$ is the intercept of the regression line for the late stage, and $t_{\mathrm{e}}$ is the initial equilibrium time. (c) Schematic diagram of surface coverage fraction with time.

$\theta_{\mathrm{e}}=\int_{0}^{t_{\mathrm{e}}}\left[k_{\mathrm{a}} x\left(1-k_{0} t\right)-k_{\mathrm{d}} k_{0} t\right] \mathrm{d} t$.

Rearrangement after integrating the right-hand side of Eq. (12) and applying the relationship of Eq. (10) to the resulting equation yields

$$
\begin{aligned}
\theta_{\mathrm{e}}= & \frac{1}{2} k_{\mathrm{a}} x t_{\mathrm{e}} \\
& =\frac{1}{2} k_{\mathrm{d}} \frac{k_{0} t_{\mathrm{e}}^{2}}{1-k_{0} t_{\mathrm{e}}} .
\end{aligned}
$$

Also, by combining Eq. (7) with Eqs. (13) and (14), $k_{\mathrm{a}}$ and $k_{\mathrm{d}}$ can be expressed as

$k_{\mathrm{a}}=\frac{2 k_{0}}{x}$,

$k_{\mathrm{d}}=\frac{2\left(1-k_{0} t_{\mathrm{e}}\right)}{t_{\mathrm{e}}}$.

Since the $k_{\mathrm{a}}$ and $k_{\mathrm{d}}$ were separately determined, the adsorption energy and desorption energy can be calculated according to the Arrhenius equation

$k_{\mathrm{a}}=S \exp \left(-E_{\mathrm{a}} / R T\right)$,

$k_{\mathrm{d}}=S \exp \left(-E_{\mathrm{d}} / R T\right)$,

where $E_{\mathrm{a}}$ and $E_{\mathrm{d}}$ represent the energy of adsorption and desorption, respectively, $S$ the frequency factor, $R$ is the universal gas constant, and $T$ denotes the absolute temperature.

\section{Materials and methods}

To demonstrate practical application of this approach, both anions and cations adsorption cases were chosen. These included:
1. selenate and selenite adsorption onto aluminum oxide coated sand (AOCS) shown in a previous paper (Kuan et al., 1998), which is anions adsorption onto filtration media;

2. $\mathrm{Mg}^{2+}$ and $\mathrm{Mn}^{2+}$ adsorption onto pure powder silica the experiments of which were conducted in this study.

Adsorption experiments of $\mathrm{Mg}^{2+}$ or $\mathrm{Mn}^{2+}$ onto $\mathrm{SiO}_{2}$ experiments were carried out using a batch technique in $50 \mathrm{ml}$ polypropylene bottles (with caps). The silica $\left(\mathrm{SiO}_{2}\right)$ used in this study was $\mathrm{Cab}-\mathrm{O}-\mathrm{Sil}$ M5 (Cabot, Tuscolca, IL), a fumed silica with a BET surface area of $200 \pm 25 \mathrm{~m}^{2} / \mathrm{g}$. Cab-O-Sil is believed to have a high proportion of free or isolated silanol groups (Abendroth, 1970; Meng and Letterman, 1993).

Before the adsorption experiments, the $\mathrm{SiO}_{2}$ suspension was aged at $25^{\circ} \mathrm{C}$ under a $\mathrm{N}_{2}$ atmosphere for $2 \mathrm{~h}$. The $\mathrm{SiO}_{2}$ concentration was maintained at $1 \mathrm{~g} / \mathrm{l}$, and the background electrolyte concentration was adjusted to $0.1 \mathrm{M}$ by $\mathrm{KNO}_{3}$ solution in all experiments. Both kinetic and equilibrium adsorptions were performed at $25^{\circ} \mathrm{C}$, and the $\mathrm{pH}$ was adjusted to $\mathrm{pH} 6 \pm 0.05$ by $\mathrm{KOH}$ and $\mathrm{HNO}_{3}$ solutions. To reduce the diffusion effect on kinetics all experiments were shaken at $200 \mathrm{rpm}$. After shaking, the samples were preserved at $4^{\circ} \mathrm{C}$ and analyzed for soluble cations either $\mathrm{Mg}^{2+}$ or $\mathrm{Mn}^{2+}$ by an Atomic Absorption Spectrophotometer (AAS, Perkin-Elmer Model 5000).

Kinetic adsorption. The initial concentration of $\mathrm{Mg}\left(\mathrm{NO}_{3}\right)_{2}$ or $\mathrm{Mn}\left(\mathrm{NO}_{3}\right)_{2}$ in the suspension was $1 \times 10^{-5}$ or $3 \times 10^{-5} \mathrm{M}$, respectively. Samples were immediately collected at various time intervals (first sample at $2 \mathrm{~min}$ ) using plastic syringes and filtered through $0.2 \mu \mathrm{m}$ membrane microfilters.

Equilibrium adsorption. Kinetic experiments suggested that pseudo-equilibrium was reached within $48 \mathrm{~h}$. So $48 \mathrm{~h}$ was chosen as the reaction time for adsorption isotherm study. The initial concentration of $\mathrm{Mg}\left(\mathrm{NO}_{3}\right)_{2}$ or $\mathrm{Mn}\left(\mathrm{NO}_{3}\right)_{2}$ was $0-1.5 \mathrm{mM}$. After the reaction period, 
the suspension was centrifuged (Kubota 6800) at 9500 rpm for $15 \mathrm{~min}$ and the supernatant was passed through a $0.2 \mu \mathrm{m}$ membrane filter.

\section{Application to actual data}

\subsection{Case1: Adsorption of selenite and selenate onto aluminum-oxide-coated sand}

Calculations of data from a previous study (Kuan et al., 1998) are shown in Fig. 2 and Table 1. The value of $x$ is the final equilibrium concentration of solute in kinetic measurements; $t_{\mathrm{e}}, \theta_{\mathrm{e}}$, and $k_{0}$ can be observed from Fig. 2 with the method shown in Fig. 1(b). Thus, $k_{\mathrm{a}}^{\mathrm{g}}$ and $k_{\mathrm{d}}^{\mathrm{g}}$ can be respectively calculated from Eqs. (15) and (16), and an equilibrium constant $\left(K_{\mathrm{geo}}\right)$ were determined by the ratio of $k_{\mathrm{a}}^{\mathrm{g}}$ to $k_{\mathrm{d}}^{\mathrm{g}}$. The deviation between the results from

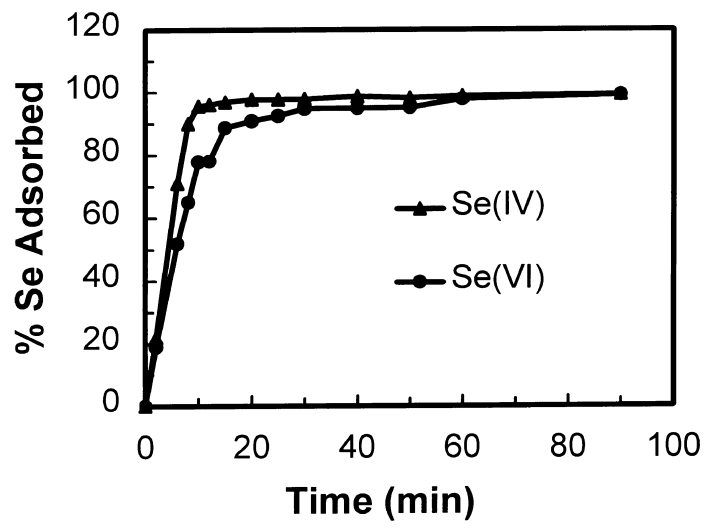

Fig. 2. Adsorption kinetics of selenite and selenate on AOCS (adapted from Ref. Kuan et al., 1998). thermodynamic and kinetic study is the key parameter to determine the feasibility of this geometric method. The results reveal that both equilibrium constants of selenate and selenite obtained by geometric kinetic calculation $\left(K_{\mathrm{geo}}\right)$ are consistent with that $\left(K_{\mathrm{con}}\right)$ obtained by fitting the Langmuir equation to experimental data of equilibrium adsorption. This proves that this approach can be applied to Se adsorption and indicates that the calculated adsorption and desorption kinetic constants are reasonable.

A number of possible steps are involved in the transfer of an adsorbate from the bulk fluid phase to the adsorption site in an adsorbent, including transport to the surface by convection or molecular diffusion, attachment to the surface, surface diffusion, dehydration, formation of a bond with the surface constituents (Stumm, 1992). Depending on the conditions of system, such as solute temperature, adsorbent diameter, adsorbent mass, agitation speed, pore size and specific surface area of adsorbent, several different types of mechanisms become dominant. Generally, high temperature, large pore size or high agitation speed will reduce diffusion effect on adsorption kinetics so that the overall rate of adsorption could be mainly controlled by the intrinsic sorption kinetics (Suzuki, 1990; Mckay, 1996). The specific surface area of adsorbent in this case has been determined as $0.2 \mathrm{~m}^{2} / \mathrm{g}$ (Kuan et al., 1998), which represents that the adsorbent has an essentially nonporous surface so that the overall rate of adsorption could be mainly controlled by intrinsic sorption kinetics. The $k_{\mathrm{a}}^{\mathrm{g}}$ of selenite $\left(1.93 \times 10^{1} \mathrm{~min}^{-1} \mathrm{mM}^{-1}\right)$ is almost 10 times larger than that of selenate $\left(1.14 \times 10^{0} \mathrm{~min}^{-1} \mathrm{mM}^{-1}\right)$, but the $k_{\mathrm{d}}^{\mathrm{g}}$ values for both are in the same order of magnitude; in both cases, $k_{\mathrm{a}}^{\mathrm{g}}$ is larger than $k_{\mathrm{d}}^{\mathrm{g}}$. Hingston et al. (1974) studied the reversibility of selenite and selenate adsorbed on goethite and gibbsite, observing that

Table 1

Calculations of $\mathrm{Se}(\mathrm{IV})$ and $\mathrm{Se}(\mathrm{VI})$ adsorption onto AOCS

\begin{tabular}{lll}
\hline & Selenite & Selenate \\
\hline Initial concentration $(\mathrm{mM}), C_{0}$, & $8.00 \times 10^{-1}$ & $8.00 \times 10^{-1}$ \\
$\mathrm{pH}_{\text {system }}$ & $4.80 \pm 0.05$ & $4.80 \pm 0.05$ \\
Equilibrium concentration $(\mathrm{mM}), x$ & $6.00 \times 10^{-3}$ & $5.60 \times 10^{-2}$ \\
Initial equilibrium time (min), $t_{\mathrm{e}}$ & 10 & 20 \\
Adsorption capacity (mg-Se/g AOCS), $Q_{\mathrm{m}}$ & $1.08 \times 10^{0}$ & $9.20 \times 10^{-1}$ \\
Equilibrium coverage fraction, $\theta_{\mathrm{e}}$ & $5.80 \times 10^{-1}$ & $6.40 \times 10^{-1}$ \\
Initial adsorption rate $\left(\mathrm{min}^{-1}\right), k_{0}$ & $5.8 \times 10^{-2}$ & $3.2 \times 10^{-2}$ \\
Adsorption rate constant $\left(\mathrm{min}^{-1} \mathrm{mM}^{-1}\right), k_{\mathrm{a}}^{\mathrm{g}}$ & $1.93 \times 10^{1}$ & $1.14 \times 10^{0}$ \\
Desorption rate constant $\left(\mathrm{min}^{-1}\right), k_{\mathrm{d}}^{\mathrm{g}}$ & $8.40 \times 10^{-2}$ & $3.6 \times 10^{-2}$ \\
Equilibrium constant $\left(\mathrm{mM}^{-1}\right), K_{\text {geo }}{ }^{\mathrm{a}}$ & $2.30 \times 10^{2}$ & $3.18 \times 10^{1}$ \\
Equilibrium constant $\left(\mathrm{mM}^{-1}\right), K_{\text {con }}{ }^{\mathrm{b}}$ & $2.24 \times 10^{2}$ & $3.32 \times 10^{1}$ \\
$\quad\left(\right.$ determination coefficient, $\left.r^{2}\right)$ & $(0.99)$ & $(0.99)$ \\
\hline
\end{tabular}

${ }^{\mathrm{a}} K_{\text {geo }}=k_{\mathrm{a}}^{\mathrm{g}} / k_{\mathrm{d}}^{\mathrm{g}}$.

${ }^{\mathrm{b}} K_{\text {con }}$ was obtained from the thermodynamic study with the Langmuir equation, which can be expressed as $\theta=K_{\text {con }} C /\left(1+K_{\text {con }} C\right)$, where $\theta$ is the surface coverage fraction and $C$ is the equilibrium concentration of adsorbate in thermodynamic studies. 
a little portion of the selenite adsorbed on goethite could be desorbed, whereas selenate adsorption on gibbsite was easily reversible. Zhang and Sparks (1990) studied the kinetics of selenate and selenite adsorption onto goethite with the pressure-jump relaxation technique, also suggesting that the intrinsic rate constant for adsorption was much larger than that for desorption. The irreversibility observed for selenite adsorption might have resulted from inner-sphere bridging, multidentate ligand, or ring-structure formation at the surface (Balistrieri and Chao, 1987; Hayes et al., 1987; Zhang and Sparks, 1990; Scott and Morgan, 1996). The results of applying this geometric method to selenite and selenate adsorption onto AOCS are apparently consistent with conclusions from other experiments and models. Moreover, this method can be easily and simply performed without the use of complicated experimental instruments.

\subsection{Case 2: Adsorption of $\mathrm{Mg}^{2+}$ and $\mathrm{Mn}^{2+}$ onto $\mathrm{SiO}_{2}$}

Fig. 3 shows the results of kinetic experiments of $\mathrm{Mg}^{2+}$ and $\mathrm{Mn}^{2+}$. Table 2 summarizes the calculated results of $\mathrm{Mg}^{2+}$ and $\mathrm{Mn}^{2+}$ acquired by this geometric approach. This method provided excellent consistency between the $K_{\text {con }}$ and $K_{\text {geo }}$ for $\mathrm{Mg}^{2+}$ but was not suitable for $\mathrm{Mn}^{2+}$ adsorption. Differences in the fit between $\mathrm{Mg}^{2+}$ and $\mathrm{Mn}^{2+}$ could be attributed to their different complex formation characteristics with metal oxide surfaces. The evidence derived from electron spin resonance (ESR) studies has shown that, when $\mathrm{Mn}^{2+}$ adsorbs on oxide surfaces, the formation of surface Mn(II)-hydroxide clusters may be much more favorable than that of monolayer adsorption or homogeneous nucleation in solution (Martini, 1981; Bleam and McBride, 1985). Consequently, a large portion of the

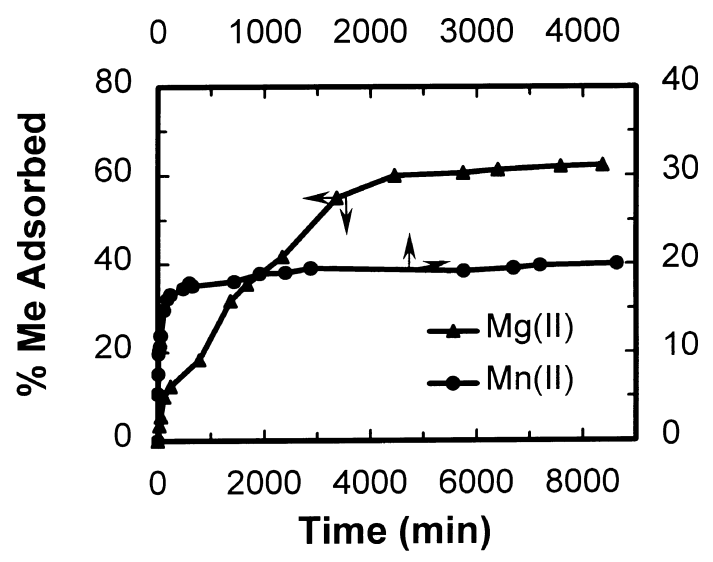

Fig. 3. Adsorption kinetics of $\mathrm{Mg}^{2+}$ and $\mathrm{Mn}^{2+}$ on $\mathrm{SiO}_{2}$.

original oxide surface remains exposed even though full adsorption occurs. The type of $\mathrm{Mn}^{2+}$ adsorption onto oxide is not the same as the monolayer adsorption postulation of Langmuir kinetics, which is the basis of this geometric approach. As a consequence, this method did not provide good conformity between the experimental equilibrium constant $\left(K_{\text {con }}, 8.15 \times 10^{-2} \mathrm{mM}^{-1}\right)$ that was found from static studies and the predicted equilibrium constant $\left(K_{\text {geo }}, 1.30 \times 10^{-1} \mathrm{mM}^{-1}\right)$ determined from the ratio of adsorption $\left(k_{\mathrm{a}}^{\mathrm{g}}\right)$ and desorption $\left(k_{\mathrm{d}}^{\mathrm{g}}\right)$ rate constants, i.e., $K_{\mathrm{geo}}=k_{\mathrm{a}}^{\mathrm{g}} / k_{\mathrm{d}}^{\mathrm{g}}$. Additionally, since the determination coefficient $\left(r^{2}\right)$ of fitting Langmuir adsorption equation to thermodynamic data is 0.78 the adsorption behavior of $\mathrm{Mn}^{2+}$ does not completely conform to the Langmuir adsorption model. As for $\mathrm{Mg}^{2+}$, it adsorbed at relatively isolated sites instead of forming hydroxide clusters on goethite surface (Bleam and McBride, 1985). The $K_{\text {geo }}$ of $\mathrm{Mg}^{2+}$ from kinetic

Table 2

Calculations of $\mathrm{Mg}^{2+}$ and $\mathrm{Mn}^{2+}$ adsorption onto pure $\mathrm{SiO}_{2}$

\begin{tabular}{|c|c|c|}
\hline & $\mathrm{Mg}^{2+}$ & $\mathrm{Mn}^{2+}$ \\
\hline Initial concentration $(\mathrm{mM}), C_{0}$ & $1.00 \times 10^{-2}$ & $3.00 \times 10^{-2}$ \\
\hline $\mathrm{pH}_{\text {system }}$ & $6.00 \pm 0.05$ & $6.00 \pm 0.05$ \\
\hline Equilibrium concentration (mM), $x$ & $6.20 \times 10^{-3}$ & $2.40 \times 10^{-2}$ \\
\hline Initial equilibrium time $(\min ), t_{\mathrm{e}}$ & $2.57 \times 10^{3}$ & $9.00 \times 10^{1}$ \\
\hline Adsorption capacity $\left(\mathrm{mg}-\mathrm{Me} / \mathrm{g} \mathrm{SiO}_{2}\right), Q_{\mathrm{m}}$ & $3.41 \times 10^{-1}$ & $1.00 \times 10^{2}$ \\
\hline Equilibrium coverage fraction, $\theta_{\mathrm{e}}$ & $3.56 \times 10^{-2}$ & $3.12 \times 10^{-3}$ \\
\hline Initial adsorption rate $\left(\mathrm{min}^{-1}\right), k_{0}$ & $1.38 \times 10^{-5}$ & $3.47 \times 10^{-5}$ \\
\hline Adsorption rate constant $\left(\mathrm{min}^{-1} \mathrm{mM}^{-1}\right), k_{\mathrm{a}}^{\mathrm{g}}$ & $4.45 \times 10^{-3}$ & $2.89 \times 10^{-3}$ \\
\hline Desorption rate constant $\left(\mathrm{min}^{-1}\right), k_{\mathrm{d}}^{\mathrm{g}}$ & $7.50 \times 10^{-4}$ & $2.22 \times 10^{-2}$ \\
\hline Equilibrium constant $\left(\mathrm{mM}^{-1}\right), K_{\mathrm{geo}}{ }^{\mathrm{a}}$ & $5.90 \times 10^{0}$ & $1.30 \times 10^{-1}$ \\
\hline Equilibrium constant $\left(\mathrm{mM}^{-1}\right), K_{\text {con }}{ }^{\mathrm{b}}$ & $5.12 \times 10^{0}$ & $8.15 \times 10^{-2}$ \\
\hline (determination coefficient, $r^{2}$ ) & $(0.92)$ & $(0.78)$ \\
\hline
\end{tabular}

${ }^{\mathrm{a}} K_{\text {geo }}=k_{\mathrm{a}}^{\mathrm{g}} / k_{\mathrm{d}}^{\mathrm{g}}$.

${ }^{\mathrm{b}} K_{\text {con }}$ was obtained from the thermodynamic study with the Langmuir equation, which can be expressed as $\theta=K_{\text {con }} C /\left(1+K_{\text {con }} C\right)$, where $\theta$ is the surface coverage fraction and $C$ is the equilibrium concentration of adsorbate in thermodynamic studies. 
measurements was $5.90 \mathrm{mM}^{-1}$, which is similar to the $K_{\text {con }}, 5.12 \mathrm{mM}^{-1}$, from equilibrium studies. Bleam and McBride (1985) also concluded that oxides have a higher capacity for adsorbing $\mathrm{Mn}^{2+}$ that tends to form surface hydroxide clusters than for $\mathrm{Mg}^{2+}$ that tends to form monolayer adsorption. Their conclusions coincide with the results in this study. In equilibrium studies, the adsorption capacity $\left(Q_{\mathrm{m}}\right)$ of $\mathrm{Mn}^{2+}$ was significantly higher than that of $\mathrm{Mg}^{2+}$ (shown in Table 2).

This geometric approach belonging to first-order type of kinetic model has been demonstrated to be applicable to ions adsorption onto $\mathrm{SiO}_{2}$ regardless of powder or granule. The criterion of good conformity is that the adsorption behavior must follow the monolayer adsorption type. Although this simple geometric method did not characterize and confirm details of the mechanism involved in adsorption reaction, the fast and experiment time-saving determination of overall kinetic constants with this approach is convenient for most industrial and scientific works. Kithome et al. (1998) reported that first-order kinetic model can be applied extensively to cation and anion sorption in soils. Boyd et al. (1947) also demonstrated this equation can describe both film diffusion-controlled reaction and chemicallycontrolled reaction for isotopic exchange conditions. Helfferich (1983) stated that other reactions known to be diffusion controlled can also be described using secondorder chemical reactions through a mathematical coincidence. Therefore, other information must then be used to determine the rate-limiting mechanism but the overall kinetic constant is enough to describe the change of adsorption reaction with time.

\section{Conclusions}

The geometric approach for directly determining both adsorption and desorption kinetic constants without the relationship of $k_{\mathrm{d}}^{\mathrm{c}}=K_{\mathrm{con}} / k_{\mathrm{a}}^{\mathrm{c}}$ has been proposed. Moreover, the geometric method is a rapid and simple technique to calculate the equilibrium constant. This method could not only reduce experimental work and calculations but also improve the accuracy of the conventional procedure in finding $k_{\mathrm{a}}^{\mathrm{c}}$ and $k_{\mathrm{d}}^{\mathrm{c}}$. Because both $k_{\mathrm{a}}^{\mathrm{g}}$ and $k_{\mathrm{d}}^{\mathrm{c}}$ could be solely obtained by kinetic experiments, the applicability of the chosen model to these experiments can be assessed by comparing the equilibrium constants from kinetic and static studies.

This geometric method described both selenite and selenate adsorption very well. Since selenite bonded more strongly to the oxide surface than selenate did, the $k_{\mathrm{a}}^{\mathrm{g}}$ of selenate was almost 10 times larger than that of selenite. The $k_{\mathrm{d}}^{\mathrm{g}}$ values of selenate and selenite were in the same order of magnitude. The reason why applying this method to $\mathrm{Mg}^{2+}$ was more feasible than to $\mathrm{Mn}^{2+}$ adsorption is that $\mathrm{Mn}^{2+}$ can form surface $\mathrm{Mn}(\mathrm{II})$ - hydroxide clusters, which is not consistent with the monolayer adsorption postulation of this method. Consequently, this method can be successfully applied to kinetic adsorption studies of adsorbates that form inneror outer-sphere complexes but not to studies of adsorbates that form cluster-like complexes.

\section{Acknowledgements}

We thank the National Science Council of Taiwan, Republic of China, NSC \#88-2218-E-002-036 for financial support.

\section{References}

Abendroth, R.P., 1970. Behavior of a pyrogenic silica in simple electrolytes. Colloid Interface Sci. 34, 591-596.

Al-Ekabi, H., Serpone, N., Pelizzetti, E., Minero, C., Fox, M.A., Draper, R.B., 1989. Kinetic studies in heterogeneous photocatalysis. 2. $\mathrm{TiO}_{2}$-mediated degradation of 4-chlorophenol alone and in a three-component mixture of 4chlorophenol, 2,4-dichlorophnol, and 2,4,5-trichlorophenol in air-equilibrated aqueous media. Langmuir 5, 250-255.

Anderson, P.R., Benjamin, M.M., 1990. Surface and bulk characteristics of binary oxide suspension. Environ. Sci. Technol. 24, 692-698.

Balistrieri, L.S., Chao, T.T., 1987. Selenium adsorption by goethite. Soil Sci. Soc. Am. J. 51, 1145-1151.

Bleam, W.F., McBride, M.B., 1985. Cluster formation versus isolated-site adsorption. A study of $\mathrm{Mn}$ (II) and $\mathrm{Mg}$ (II) adsorption on boehmite and goethite. Colloid Interface Sci. 103, 124-132.

Boyd, G.E., Adamson, A.W., Myers Jr., A.S., 1947. The exchange adsorption of ions from aqueous solution by organic zeolites: II. Kinetics. J. Am. Chem. Soc. 69, 28362848.

Davis, A.P., Upadhyaya, M., 1996. Desorption of cadmium from goethite ( $\alpha$-FeOOH). Water Res. 30, 1894-1904.

Dzombak, D.A., Morel, F.M.M., 1986. Sorption of cadmium on hydrous ferric oxide at high sorbate/sorbent ratios: equilibrium, kinetic, and modeling. Colloid Interface Sci. 112, 588-598.

Fox, M.A., Dulay, M.T., 1993. Heterogeneous photocatalysis. Chem. Rev. 93, 341-357.

Hayes, K.F., Roe, A.L., Brown, G.E., Hodgson, K.O., Leckie, J.O., Parks, G.A., 1987. In situ X-ray absorption study of surface complexes: selenium oxyanions on $\alpha-\mathrm{FeOOH}$. Science 238, 783-786.

Helfferich, F.G., 1983. Ion exchange kinetics - evolution of a theory. In: Liberti, L., Helfferich, F.G. (Eds.), Mass Transfer and Kinetics of Ion Exchange. Martinus Nijhoff, Boston, pp. 157-159.

Hingston, F.J., Posner, A.M., Quirk, J.P., 1974. Anion adsorption by goethite and gibbsite: II. Desorption of anions from hydrous oxide surfaces. J. Soil Sci. 25, 16-26.

Hoffmann, M.R., Martin, S.T., Behnemann, D.W., 1995. Environmental applications of semiconductor photocatalysis. Chem. Rev. 95, 69-96. 
Kithome, M., Paul, J.W., Lavkulich, L.M., Bomke, A.A., 1998. Kinetics of ammonium adsorption and desorption by the natural zeolite clinoptilolite. Soil Sci. Soc. Am. J. 62, $622-629$.

Kuan, W.H., Lo, S.L., Wang, M.K., Lin, C.F., 1998. Removal of $\mathrm{Se}(\mathrm{IV})$ and $\mathrm{Se}(\mathrm{VI})$ from water by aluminum-oxide-coated sand. Water Res. 32, 915-923.

Langmuir, I., 1918. The adsorption of gases on plane surfaces of glass, mica and platinum. Am. Chem. Soc. 40, 13611403.

Lin, C.F., Benjamin, M.M., 1992. The effects of strongly complexing ligands on the adsorptive partitioning of metal ions. Water Res. 26, 397-407.

Martini, G., 1981. The state of water adsorbed on silica gel as determined by ESR of transition metal ion probe. Colloid Interface Sci. 80, 39-48.

Mckay, G., 1996. Use of Adsorbents for the Removal of Pollutants from Wastewaters. CRC Press, Boca Raton, FL.

McLaren, R.G., Backes, C.A., Rate, A.W., Swift, R.S., 1998. Cadmium and cobalt desorption kinetics from soil clays: effect of sorption period. Soil Sci. Soc. Am. J. 62, 332-337.

Meng, X., Letterman, R.D., 1993. Effect of component oxide interaction on the adsorption properties of mixed oxides. Environ. Sci. Technol. 27, 970-975.

Mizuno, N., Misono, M., 1998. Heterogeneous catalysis. Chem. Rev. 98, 199-217.

Moore, J.W., Pearson, R.G., 1981. Kinetics and Mechanism. Wiley, New York.
Pullukat, T., Hoff, R., 1999. Silica-based ziegler-natta catalysts: a patent review. Catal. Rev.-Sci. Eng. 41, 389-428.

Rate, A.W., McLaren, R.G., Swift, R.S., 1993. Response of copper(II)-humic acid dissociation kinetics to factors influencing complex stability and macromolecular conformation. Environ. Sci. Technol. 27, 1408-1414.

Reid, J.D., NcDuffie, B., 1981. Sorption of the trace cadmium on clay minerals and river sediments: effects of $\mathrm{pH}$ and Cd(II) concentrations in a synthetic river water. Water, Air, Soil Pollut. 15, 375-386.

Scott, M.J., Morgan, J.J., 1996. Reactions at oxide surfaces. II. Oxidation of $\mathrm{Se}(\mathrm{IV})$ by synthetic birnessite. Environ. Sci. Technol. 30, 1990-1996.

Sparks, D.L., 1986. Kinetics of reactions in pure and in mixed systems. In: Sparks, D.L. (Ed.), Soil Physical Chemistry. CRC press, Boca Raton, FL, pp. 83-145.

Sparks, D.L., 1988. Kinetics of Soil Chemical Process. Academic Press, San Diego.

Steinfeld, J.I., Francisco, J.S., Hase, W.L., 1999. Chemical Kinetics and Dynamics. Prentice-Hall, Englewood Cliffs, NJ.

Stumm, W., 1992. Chemistry of the Solid-Water Interface: Processes at the Mineral-Water and Particle-Water Interface in Natural Systems. Wiley, New York.

Suzuki, M., 1990. Adsorption Engineering. Elsevier, New York.

Zhang, P.C., Sparks, D.L., 1990. Kinetics of selenate and selenite adsorption/desorption at the goethite/water interface. Environ. Sci. Technol. 24, 1848-1856. 